\title{
A IMPORTÂNCIA DO CONTEXTO HISTÓRICO: EL SALVADOR E IGNÁCIO MARTÍN-BARÓ
}

\author{
LA IMPORTANCIA DEL CONTEXTO HISTÓRICO: \\ EL SALVADOR E IGNACIO MARTÍN-BARÓ \\ THE IMPORTANCE OF HISTORICAL CONTEXT: \\ EL SALVADOR AND IGNÁCIO MARTÍN-BARÓ
}

\author{
Maria Fernanda Costa Waeny ${ }^{1}$ e Cibele Mariano Vaz de Macêdo ${ }^{1}$ \\ ${ }^{1}$ Universidade Ibirapuera, São Paulo/SP, Brasil
}

\begin{abstract}
RESUMO: Os escritos de Ignácio Martín-Baró estão estreitamente vinculados ao contexto histórico e à situação política e social de El Salvador. O alinhamento entre oligarquia, forças armadas e clero, intervenções externas na economia e política e interesses geopolíticos geraram graves conflitos políticos e sociais, guerra civil e profunda crise social nesse país. Esse quadro de forças se alterou ao longo do tempo. O objetivo é apresentar dados históricos sobre El Salvador e região, demonstrar a importância do contexto histórico e como eles podem ampliar a compreensão sobre o pensamento e a obra de Martín-Baró, bem como a sua proposta acerca do papel do psicólogo neste cenário. PALAVRAS-CHAVE: Psicologia Social; História da Psicologia; Psicologia Crítica; Ignácio Martín-Baró.
\end{abstract}

RESUMEN: Los escritos de Ignacio Martín-Baró están estrechamente vinculados al contexto histórico ya la situación política y social de El Salvador. La alineación entre oligarquía, fuerzas armadas y clero, intervenciones externas en la economía y política e intereses geopolíticos generaron graves conflictos políticos y sociales, guerra civil y profunda crisis social en ese país. Este cuadro de fuerzas se ha alterado a lo largo del tiempo. El objetivo es presentar datos históricos sobre El Salvador y región, demostrar la importancia del contexto histórico y cómo pueden ampliar la comprensión sobre el pensamiento y la obra de Martín-Baró, así como su propuesta acerca del papel del psicólogo en este escenario.

PALABRAS CLAVE: Psicología Social; Historia de la Psicología; Psicología Crítica; Ignácio Martín-Baró.

ABSTRACT: The writings of Ignácio Martín-Baró are closely linked to the historical context and the political and social situation of El Salvador. The alignment between the oligarchy, the armed forces and the clergy, external interventions in the economy and politics and geopolitical interests have generated serious political and social conflicts, civil war and deep social crisis in that country. This relationship of forces has changed over time. The objective is to present historical data about El Salvador and the region, to demonstrate the importance of the historical context and how they can broaden the understanding about the thought and work of Martín-Baró, as well as his proposal about the role of the psychologist in this scenario.

KEYWORDS: Social Psychology; History of Psychology; Critical Psychology; Ignácio Martín-Baró. 


\section{Introdução}

A história da América Central demonstra a relevância dessa região para a geopolítica mundial. Sua condição agroexportadora, as oligarquias dominantes, o canal do Panamá ou sua proximidade a Cuba, entre outros fatores, fizeram dela uma região de disputas políticas, ditadura civil e militar, intervenção internacional e palco de sangrentas guerras civis.

O psicólogo Ignácio Martín-Baró abordou os problemas do povo salvadorenho a partir do contexto do período, indicando propostas para enfrentar a situação política e social de El Salvador, sendo o país que adotou para si. Sua produção intelectual e sua prática estiveram intimamente vinculadas ao contexto de El Salvador e enfatizavam temas e problemas relativos aos salvadorenhos. Entre seus objetos de estudo estavam: o machismo (1968), os processos de aglomeração (1973a), a saúde mental (1984b), o fatalismo (1987), a violência (1988) e a guerra (1981, 1989a).

Martín-Baró (1996) entendia que o trabalho do psicólogo deveria ser baseado em teorias e práticas desenvolvidas localmente e voltadas para a realidade em que estava inserido. Para tanto, propôs que psicólogos da América Central orientassem sua atuação em três níveis: partir das condições concretas da sociedade; partir das necessidades da maioria da população; e encontrar respostas para a injustiça social, os conflitos armados, a perda da soberania e a identidade alienada de seu povo. Desta forma, para ele, seria papel do psicólogo "intervir nos processos subjetivos que sustentam e viabilizam estruturas injustas" (p. 22); "ajudar a encontrar caminhos para substituir hábitos violentos por hábitos mais racionais [e] contribuir para a formação de uma identidade, pessoal e coletiva, que responda às exigências mais autênticas dos povos" (Martin-Baró, 1996, p. 22).

Nesse sentido, para apreender diferentes âmbitos do tema abordado propõe-se recuperar aspectos históricos da região, ampliar o contexto com dados e fontes mais recentes, retornar a alguns escritos de Martín-Baró e avaliar a repercussão dessa proposta em El Salvador.

Para cumprir este objetivo, será abordado um breve histórico político da região, a importância da América Central na geopolítica mundial e as formas de atuação dos Estados Unidos na região; em seguida, será analisado como o conhecimento mais aprofundado do contexto histórico pode ampliar a compreensão dos eventos e das propostas de Martín-Baró.

\section{Breve histórico da emancipação política da América Central e de El Salvador}

O Reino da Guatemala conquistou sua independência do Império Espanhol em 1821 , sendo depois desmembrado nas províncias que atualmente integram a América Central. De modo geral, nesta região, houve uma constante busca pela emancipação democrática e soberania perante as oligarquias e coalizões políticas dominantes. Resultou deste quadro uma profunda e duradoura crise política (com fraudes eleitorais, golpes de estado, ditaduras), econômica (dependência de capital externo, planos de recuperação) e social (luta armada, sequestros, assassinatos, violação aos direitos humanos).

O caso de El Salvador não difere deste panorama geral. Sue-Montgomery e Wade (2006) dividem a história política de El Salvador em quatro momentos principais: 
O primeiro período (1850-1932) foi da expansão cafeeira; a concentração da posse da terra forçou camponeses a trabalharem para os latifundiários; estreitou-se a relação entre igreja, elite e exército; o movimento trabalhista se organizou; e a primeira insurreição comunista, em 22 de janeiro de 1932, vitimou trinta mil civis, mais o líder e herói nacional, Augustín Farabundo Martí (1893-1932) (Gómez, 1971).

No segundo período (1932-1948) ocorreu a coalizão entre oligarquia e exército, centralização do poder e controle sobre as organizações campesinas e sindicatos; golpes de estado ficaram mais frequentes e duros.

O terceiro período (1948-1979) foi do regime militar institucional; os partidos políticos representavam diferentes correntes do próprio exército; a oposição não elegia candidatos, e chapas religiosas ou financiadas pelo exterior eram excluídas.

O quarto período (1960-1972) se sobrepõe ao anterior e foi de relativa abertura; os partidos políticos se organizaram; os sindicatos, Comunidades Cristãs de Base e demais organizações populares cresceram; o comércio intrarregional se ampliou, propiciando a criação de um mercado comum; porém, diante do risco de ascensão dos partidos de esquerda, oligarquia e exército se uniram e manipularam as eleições; a insatisfação popular resultou em repressão, seguida por uma longa e sangrenta guerra civil a partir de 1980 .

Um dos momentos culminantes da guerra civil foi a ofensiva final da Frente Farabundo Martí para Libertação Nacional (FMLN), em novembro de 1989, quando foram assassinados jesuítas e funcionários da Universidad Centroamericana José Simeón Cañas (UCA).

\section{América Central: zona estratégica e formas de atuação na região}

A América Central era uma zona de interesse para os Estados Unidos (EUA); conforme documento citado por Hardy (1984), já em 1927 o Departamento de Estado dos EUA afirmava que "os governos da América Central devem entender que permanecem no poder quando recebem nosso respaldo e, ocorrendo o contrário, são depostos. Isto acontece porque na região estão nossos interesses" (p. 21).

Ao longo do tempo, porém, os EUA atuaram com diferentes objetivos: logo após a II Guerra Mundial, promoveram o setor privado (Bulmer-Thomas, 1996); o governo Carter (1977-1981) a transformou em modelo para reorganização econômica dos países em desenvolvimento; o governo Reagan (1981-1989) demonstrou seu poderio armamentista e militar contra o comunismo (Maira, 1982).

No decorrer do tempo, contudo, as formas de atuação na região se alteraram; descrevem-se, a seguir, algumas formas de atuação dos EUA na região.

\section{A United Fruit Company}

A banana era uma fruta praticamente desconhecida até 1876, quando foi apresentada na Exposição da Independência Americana; cerca de vinte anos mais tarde, em 1898, a importação da fruta alcançou a cifra de dezesseis milhões de cachos, sendo que "mais de uma centena de empresas importavam e comercializavam banana para os Estados Unidos" (May \& Plaza, 1958, p. 5); desde então empresas e subsidiárias têm comercializado banana e outros produtos tropicais da região. 
Ao longo do tempo, as várias empresas (entre as quais Tropical Trading and Transport, Colombia Land, Snyder Banana, Boston Fruit, Bluefields Steamship, Cuyamel Fruit, Vaccaro Brothers, Standard Fruit, United Fruit, United Brands, Chiquita Brands International) foram incorporadas pela United Fruit Corporation (Iunai). Fundada em 1899, a Iunai se tornou a principal companhia a atuar na região.

Sua presença e influência foram tão fortes que até mesmo reconhecidos escritores a mencionaram. Em seu Canto geral, Pablo Neruda (Neruda, 1950/2010) escreve "a Compañía Frutera Inc. reservou para si o mais suculento, a costa central de minha terra, a doce cintura da América. Batizou de novo suas terras como 'Repúblicas Bananas'” (p. 214). Gabriel Garcia Marques (Marques, 1967/2014) relata “os trabalhadores reivindicavam que não os obrigassem a cortar e embarcar banana aos domingos" (p. 332) e que José Arcádio Segundo "tinha renunciado ao cargo de capataz de turno da companhia bananeira e tomou partido ao lado dos trabalhadores” (p. 332). Ainda hoje a United Fruit é objeto e/ou citada em pesquisas (Bologna, 2013; Bruit, 1985; Bucheli, 2005; Koeppel, 2007; Silva, 2016; Vergara, 2010).

Para garantir o plantio, escoamento e distribuição da produção foi imprescindível modernizar a infraestrutura disponível na região. Para escoar a produção, em 1904 a Iunai construiu a International Railways of Central America, sobre uma malha ferroviária regional existente desde 1897. Para coordenar o tráfego e os carregamentos dos produtos a Iunai passou a utilizar a Tropical Radio Telegraph Company, em funcionamento desde 1904, cuja transmissão alcançava também algumas das grandes cidades ao redor do mundo (May \& Plaza, 1958). A Fruit Dispatch Company distribuía e organizava a exportação dos produtos por intermédio de subsidiárias na Europa e Canadá (May \& Plaza, 1958). A ampliação da infraestrutura propiciada pelas fazendas e empresas instaladas na região, portanto, se realizou a partir de um modelo exclusivamente agroexportador.

\section{O Canal do Panamá}

Desde o século XIX há projetos para a construção de uma rota interoceânica através da América Central; ela significaria maior segurança na navegação, encurtamento das rotas marítimas e redução de custos. Um dos primeiros projetos foi proposto em 1878, pelo engenheiro francês Ferdinand de Lesseps, construtor do Canal de Suez; iniciado em 1881, o projeto foi abandonado por problemas de engenharia e pela alta mortalidade decorrente das doenças tropicais; no início do século XX os EUA assumiram o projeto, e cerca de uma década depois, em agosto de 1914, o canal foi finalmente inaugurado.

A obra garantiu economia de quase cinco mil quilômetros nas rotas interoceânicas e facilitou o comércio entre as costas leste-oeste dos EUA; a travessia dura menos de vinte e quatro horas e tem servido a mais de dez mil navios por ano; sob concessão dos EUA até 1999, sua administração lhes garantiu parte do controle sobre o comércio marítimo internacional.

Além de corredor marítimo durante a II Guerra Mundial e de ser a menor e mais segura rota entre o Atlântico e o Pacífico, o Canal do Panamá é ponto estratégico no âmbito geopolítico. Siegfried (1945) esclarece que os navios que transitam pelas rotas do Canal de Suez e Canal do Panamá “refletem com precisão o equilíbrio global do planeta” (p. 298); 
isto é, haveria duas áreas importantes para o comércio marítimo internacional, uma "com o Suez como eixo, que se expressa principalmente no comércio entre a Europa e Ásia; outra, com o Panamá como eixo, que se expressa pelo comércio entre o Atlântico e o Pacífico" (pp. 299-300). Isto significa que interessava aos EUA controlar uma das duas principais rotas marítimas internacionais.

\section{Guerra Fria e estratégias de defesa}

A Guerra Fria surgiu ao fim da II Guerra Mundial; o mundo se dividiu em dois blocos opositores, tendo como base o poderio nuclear das duas superpotências: EUA versus URSS, ocidente versus oriente, capitalismo versus comunismo.

Um marco foi o ano de 1947. Em março, o então o presidente americano, Harry Truman, alegou que a segurança dos EUA estaria em perigo em qualquer local que o comunismo tentasse se impor; para se defender desse risco, os EUA formularam a Doutrina da Segurança Nacional (DSN) (sobre a DSN, consultar Comblin, 1980; Montagna, 1986). Era imprescindível se proteger do comunismo, fosse este sob a forma de uma provável agressão externa ou uma possível subversão interna; ou seja, se proteger tanto de uma declaração de guerra quanto pela tomada de poder imposto por comunistas infiltrados na população civil. Assim, em setembro de 1947, os países do continente americano assinaram o Tratado Interamericano de Assistência Recíproca (TIAR), determinando que o ataque a um dos membros seria um ataque a todos os seus signatários. Ou seja, um acordo de defesa mútua que integrava todo o bloco das Américas.

Para os EUA, a Revolução Cubana, de 1959, representou uma nova ameaça do comunismo sobre as Américas; este risco eminente suscitou intervenções para defender o possível avanço insurgente na região. Porém, pelo ideário do TIAR e da DSN, o combate ao comunismo deveria ser externo e interno; ou seja, tanto defender territórios da invasão comunista quanto impedir a ascensão do comunismo dentro da própria sociedade.

Durante a Guerra Fria, o ideário do TIAR e da DSN aproximou os EUA dos demais países americanos; este contexto alavancou diversas ações protagonizadas pelos EUA, entre as quais criar a Escola das Américas, visando preparar oficiais e ministrar cursos sobre temas militares; fomentar a criação de Escolas Superiores de Guerra nos países amigos; qualificar e treinar militares para ações anticomunismo; treinar oficiais para obter informações (infiltração de agentes e informantes, interrogatórios, torturas etc.); promover intercâmbio de dados, fornecer equipamentos, armamentos e financiamentos. A ameaça comunista, portanto, possibilitou o predomínio político e estratégico dos EUA sobre todo o continente americano.

\section{As propostas dos Estados Unidos para a região}

Rosa e Suay (1986) analisam três planos dos EUA para a recuperação econômica da região; são eles: Documento de Santa Fé (maio/1980), Iniciativa de la Cuenca del Caribe (agosto/1983) e o Informe Kissinger (janeiro/1983). As propostas privilegiavam ora um país, ora a região; segundo o Informe Kissinger, por exemplo, “a crise não pode ser con- 
siderada em termos econômicos ou políticos ou sociais ou de segurança. O futuro desenvolvimento da América Central é um tecido sem costuras. As recomendações que fazemos tratam de enfocar esta complexa interrelação" (citado por Rosa \& Suay, 1986, p. 16).

Apesar das diferenças de perspectiva, se regional ou continental, há certa unidade quanto aos objetivos nos planos propostos pelos EUA: eliminar o Estado da esfera produtiva, mas o mantendo como base para os bens sociais (saúde, educação) e da administração estatal (justiça, finanças); ampliar vínculos entre as economias da região e os EUA através do livre comércio; ofertar crédito e manter a agricultura tradicional; diversificar o cultivo e fomentar a agricultura de exportação; comprar e refinanciar a dívida; promover a absorção da força de trabalho local, evitando migrações; desenvolver a indústria a partir da iniciativa doméstica, fomentando a pequena empresa e minimizando a dependência do capital externo; dar isenção fiscal às empresas americanas; incluir os EUA na administração de organismos regionais (Rosa \& Suay, 1986). Ou seja, desenvolver a região e manter certo grau de dependência, de modo a garantir a hegemonia norte-americana.

\section{As propostas dos Estados Unidos para El Salvador}

As propostas de desenvolvimento dos EUA para El Salvador mostram que a estratégia foi combater o comunismo, estabilizar e desenvolver o país e ampliar o domínio de modo a garantir os interesses dos EUA. O comunismo foi enfrentado através da ajuda militar e econômica para combate à guerrilha e a FMLN. A retomada econômica e o desenvolvimento seriam alcançados por meio dos planos propostos pela Agência para o Desenvolvimento Internacional (AID).

Todavia, os planos demonstram a pretensão hegemônica dos EUA sobre El Salvador e região: recuperação e estabilização da economia e do setor produtivo; crescimento real do PIB, financiamento do FMI para equilibrar a balança comercial, o déficit fiscal e ajustar a taxa de câmbio; garantir a produção alimentar, restaurar a confiança do setor privado, restaurar os serviços públicos e a atividade agrícola, reativar propriedades abandonadas, emitir títulos de propriedade privada, aumentar eficiência comercial, expandir o crédito, incentivar a exportação. O trecho de um desses documentos especifica alguns desses objetivos:

desenvolvimento das exportações não tradicionais, particularmente produtos manufaturados para venda fora do Mercado Comum Centro-Americano. A assistência da AID se centra na diversificação agrícola, na criação de novas agroindústrias, no desenvolvimento de mercado americano para as exportações não tradicionais salvadorenhas... elaborar legislação condizente ao desenvolvimento das exportações e ao investimento estrangeiro. Outros programas dão assessoria à expansão da participação das pequenas e micro empresas na economia salvadorenha. (citado por Rosa \& Suay, 1986, p. 27)

O programa prevê também assistência social e humanitária, financiar "pessoas deslocadas, reinstalar refugiados, ajudar comunidades marginais, gerar emprego, melhorar o sistema de saúde e educação e assessorar na implantação de programas de planejamento familiar" (citado por Rosa \& Suay, 1986, p. 27). 
Rosa e Suay (1986) esclarecem que alguns desses pontos foram expressamente citados nos planos propostos para El Salvador: o Programa de Reativação Econômica, de 1984, previa gerar emprego, absorver matéria prima nacional, controlar o déficit fiscal, oferecer fomento à exportação. O Plano Nacional, dos anos 1985-1989, previa equilibrar e melhorar a administração financeira, fomentar a exportação não tradicional, refazer a infraestrutura.

Rosa e Suay (1986) citam ainda duas outras propostas de desenvolvimento que foram apresentadas no mesmo período 1985-1989: (a) Projetos Concretos de Desenvolvimento e (b) Pré-Plano ao setor não formal. A primeira proposta propõe macroprojetos visando: garantir a democracia através da difusão da cultura e alfabetização (Projeto PAS); semear grãos e garantir autossuficiência alimentícia (Projeto SURCO); criar e desenvolver empresas para garantir emprego e assistência técnica (Projeto CONFE); assentar a população deslocada ou marginalizada (Projeto PROMIL); pagar dívidas e recuperar postos de trabalho do sistema privado (Projeto Reativação); diminuir a influência do governo na esfera produtiva, deixando a produção para a iniciativa privada (Projeto Produtividade). A segunda proposta ressalta a importância do trabalho informal para a economia do país, e seu papel complementar em relação à grande empresa. Observa-se, nestes planos, quando não a explícita dependência econômica, pelo menos uma estreita relação comercial, e em alguns casos a participação mais efetiva dos EUA em El Salvador.

Cada conjunto de dados mostra diferentes formas de atuação dos EUA na região; este conjunto, somado a alguns aspectos apresentados a seguir, ao serem considerados em sua totalidade, contribuem para que se compreenda a importância do contexto histórico nas proposições de Martín-Baró; isto porque sua vida, sua obra e ação prática estão intimamente vinculadas à situação de El Salvador e à história da região.

\section{A importância do contexto para a análise histórica}

Tentativas para integrar a região só se concretizaram com a criação do Mercado Comum Centro Americano (MCCA), em 1960; mas a deterioração do quadro político e social, a intervenção militar e até mesmo tragédias naturais inviabilizaram o projeto. Em 1988, um acordo amparado pela ONU, e depois pela Comunidade Europeia e EUA, impulsionou a integração da região: o então denominado "Plano de Ação Imediata" previa a reintegração da região, assistência aos refugiados, ajuda alimentar, reativação econômica da região, segurança energética e administração da dívida externa, entre outras ações (López Cervantes, 2012).

O Canal do Panamá foi controlado pelos EUA desde sua inauguração, em 1914, até 1977, quando passou à administração conjunta EUA-Panamá. Em 1999, o Panamá assumiu integralmente o controle do canal; reformas para alargá-lo e aprofundá-lo o adaptaram aos navios de grande porte da nova frota marítima internacional. Deste modo, observa-se, apesar de certa autonomia da região, seja pelo MCCA ou pela administração do canal, que esta só teve início de fato no final da década de 1980.

A Iunai tinha baixo desempenho na economia nacional dos EUA; porém, quando comparada aos locais de interesse dos EUA, seu desempenho era excelente (May \& Plaza, 1958); ou seja, o lucro da Iunai provinha do exterior, isto é, de sua atuação na América 
Central e região. Em 1989, após quase cem anos de sua fundação, ela alterou a razão para Chiquita Brands International; o site da Chiquita, porém, nada menciona do passado escuso da Iunai; diz que a política atual é de responsabilidade social e ambiental, extensão dos direitos trabalhistas, proteção ao meio ambiente e às comunidades do entorno; afirma que respeito, integridade, oportunidade e responsabilidade são a base para "nosso desempenho nos negócios e orientam nossas atividades cotidianas" (http://www.chiquita.com). Este silêncio sobre os antecedentes da Chiquita Brands a desvincula de seu passado e a exime de sua pregressa hegemonia sobre a América Central e região.

A Igreja foi uma aliada da oligarquia e do poder militar salvadorenho até fins de 1960. Contudo, na década de 1970, após deliberações do Concílio Vaticano II e das conferências de Medellín e Puebla, setores da igreja latino-americana voltaram sua atenção para as desigualdades sociais e para os grupos sociais historicamente oprimidos (Sobrino, 1991). Esta mudança de perspectiva auxilia a compreender o assassinato de clérigos em El Salvador: Nicolás Rodríguez (em 1972), Padre Rutilio (em 1977), Monsenhor Romero (em 1980), o assassinato dos jesuítas da UCA (em 1989); além do mais, eles também foram hostilizados com bombas, roubos, capturas, violação de suas residências e/ou igrejas (Hardy, 1984) e mais de sessenta foram expulsos ou forçados a deixar o país (Sue-Montgomery, 2006) "em nome do anticomunismo por uma democracia ocidental e cristã” (Kolvenbach, 1989, p. 5).

Um dos motivos para a hostilidade e desconfiança dos militares em relação à UCA surgiu a partir das experiências comunitárias com camponeses coordenadas pelo padre Rutilio, entre 1972 e 1977; elas contaram com a participação de professores da UCA (Kolvenbach, 1989), e, provavelmente, foi um dos fatores que gerou suspeita da cúpula militar em relação à atuação dos padres jesuítas (Equipo Envio, 1990a); esta suspeita foi depois amplificada pela viagem do reitor Ignácio Ellacuría à Manágua para negociar com a FMLN (Equipo Envio, 1990b). Tal suspeita pode ter motivado ações militares na UCA: além de alvo de bombas constantes, a UCA foi visitada por militares dias antes do assassinato dos jesuítas e cercada pelo temido batalhão Atacatl na ofensiva final da FMLN de 1989 (Kolvenbach, 1989).

A participação do exército no assassinato da UCA foi ficando cada vez mais evidente no decorrer das investigações: dias antes do assassinato, militares estiveram na UCA fazendo reconhecimento do local e da disposição dos cômodos (Kolvenbach, 1989); uma vizinha da UCA relatou ter ouvido "Esta noite vamos matar Ellacuría e todos... aí dentro" (Kolvenbach, 1989, p. 7); jornais noticiaram uma reunião do alto escalão na noite anterior ao assassinato da UCA (Equipo Envio, 1990b); os depoimentos sobre a sucessão dos eventos (Equipo Envio, 1990b); e por fim a própria declaração do presidente Cristiani sobre a participação das Forças Armadas (Equipo Envio, 1990b).

O documento Notorious Graduates from El Salvador ( $\underline{\text { http://www.soaw.org/about- }}$ -the-soawhinsec/soawhinsec-grads/notorious-grads/238-notorious-graduates-from-el-salvador) relaciona militares salvadorenhos que cursaram a Escola das Américas e respectivas ações nos eventos durante a guerra civil de El Salvador. Roberto D'Aubisson, por exemplo, é citado por planejar e ordenar o assassinato do monsenhor Oscar Romero, ainda em 1980. Desse documento, constam também militares de alto escalão diretamente envolvidos no assassinato dos jesuítas, em 1989: Rafael Larios, Juan Rafael Bustillo, Juan Orlando Zeped, Inocente Orlando Montano, Francisco Fuentes e Carlos Barahona, citados por planejar a ação; após o assassinato, Fuentes teria dito: "ainda estamos matando comunistas, Ellacuría e Martín-Baró caíram, entreguem-se” (p. 3); Barahona sugeriu usar 
um rifle AK-47 da FMLN e deixar propaganda da FMLN no local; Nelson Lopez y Lopez, embora encarregado de investigar, encobriu o assassinato. Com base no que aprenderam na Escola das Américas, os militares salvadorenhos planejaram o ataque, intimidaram vítimas e forjaram provas para se isentarem da responsabilidade pelo assassinato dos jesuítas.

Os cerca de dez anos de duração da guerra civil forçou a mudanças estratégicas dentro da própria FMNL: as diferentes forças revolucionárias se unificaram em torno da FMLN (Sue-Montgomery \& Wade, 2006); houve uma rápida capacitação do movimento, pois "em apenas três anos a FMLN converteu um núcleo guerrilheiro e um movimento de massa radical em um grande exército revolucionário quase profissional, o qual conduziu as Forças Armadas a ponto de um colapso” (Miles \& Ostertag, 1991, p. 219); como nova estratégia, passou a recrutar todo tipo de pessoas (Miles \& Ostertag, 1991). Por outro lado, o governo falhou nas tentativas de negociação; o presidente não ofereceu garantias concretas de liberdade e segurança aos rebeldes; apesar das negociações em curso, atentados e bombas continuavam a ocorrer. Tudo indicava que as negociações não eram conduzidas com seriedade pelo governo, motivo pelo qual a FMLN executou sua ofensiva final de 1989 (Sue-Montgomery \& Wade, 2006).

As propostas para El Salvador estão em consonância com os objetivos da política econômica dos EUA para a região (Rosa \& Suay, 1986): promove-se a autonomia do país, seu equilíbrio fiscal e econômico; o desenvolvimento e a produção cabem à iniciativa privada; e a preferência comercial com os EUA e sua participação em alguns dos organismos do país garante a permanência de suas empresas e de sua hegemonia sobre a região.

A proteção do bloco ocidental contra o avanço comunista se baseou na DSN e no TIAR, e ambas legitimaram interferências dos EUA em países do continente americano. Esta prática, porém, além de intervenções e hegemonias em locais de interesse dos EUA, "resultou em regimes repressivos, marcados por um profundo autoritarismo e uma cultura de medo, que se irradiou pelo conjunto das sociedades da região, deixando sequelas que persistiram, inclusive, mesmo após o fim do ciclo das ditaduras” (Padrós, 2007, p. 30).

Os diferentes determinantes históricos, globais e locais, conexões entre os eventos, mudanças no interior dos próprios grupos organizados (a Igreja, a FMLN), ampliam a compreensão do contexto daquele período em El Salvador; este contexto, por sua vez, contribui para compreender melhor os temas e propostas elaboradas por Martín-Baró. Sob esta perspectiva alguns de seus escritos são a seguir analisados.

\section{Aspectos do contexto histórico em escritos de Ignácio Martín-Baró}

Dentre suas pesquisas, Martín-Baró (1983a) investigou a percepção dos salvadorenhos sobre um dos planos de Reagan para El Salvador (provavelmente o Documento de Santa Fé). A pesquisa indicou que a percepção dos salvadorenhos é que os EUA querem aniquilar os revolucionários e que tal atitude inviabilizaria qualquer diálogo, mesmo sendo esta a melhor saída para resolver o conflito. Para Martín-Baró (1983a), este plano teria o mesmo destino funesto do anterior e "ainda que tenha sido uma política 'para' os salvadorenhos, é certamente um plano 'sem' os salvadorenhos” (p. 522). Os planos econômicos propunham relativa autonomia, mas mantinham garantidos os interesses e a hegemonia dos EUA na região (Rosa \& Suay, 1986); assim, apenas relativamente os indivíduos eram contemplados e, portanto, tratava-se de fato de um plano sem os salvadorenhos. 
Martín-Baró (1984a) analisou a proposta do governo Reagan de "luta contra o terrorismo" (p. 813). Após definir as características do terrorismo tomando como exemplo o caso da Nicarágua, ele chegou a três conclusões: o governo mente ao povo americano, ao congresso e ao mundo sobre o que ocorre na América Central; há um cinismo moral manifesto, que aceita os meios e métodos do terrorismo quando realizados pelos "lutadores da liberdade" (p. 816), mas condena os que forem exercidos pelos opositores; e denuncia que o manual do guerrilheiro elaborado pela CIA defende que somente através do terrorismo será possível vencer a guerra na Nicarágua. Mesmo sem ter acesso aos documentos relativos ao ideário da Escola das Américas, do TIAR e da DSN, Martín-Baró identificou estratégias e formas de dominação dos EUA, pois alguns documentos só foram revelados em período posterior ao assassinato dos jesuítas, em 1989.

Em 1986, Martín-Baró fundou o Instituto Universitário de Opinião Pública (IUDOP). Seu objetivo foi identificar os problemas nacionais, as demandas e formas de resolução dos problemas a partir da percepção e respostas dos próprios salvadorenhos. A pesquisa de campo, "Opinião do povo sobre a paz em El Salvador, Pesquisa de opinião pública para o Debate Nacional", foi especialmente importante, porque abrangeu o país inteiro e antecedeu um debate nacional sobre a crise do país; ela ocorreu de 18 de julho a 11 de agosto de 1988, totalizando 1266 respondentes; os temas abordados foram a situação do país, suas causas e sugestões para superar a crise. Para quarenta por cento da população pesquisada a resolução da crise dependia da retomada do diálogo e da negociação, da flexibilização das partes, de por os interesses do povo acima de todos os outros interesses e formular acordos mínimos para o avanço nas negociações de paz (Debate Nacional de 1988). Ou seja, para a população representada pela pesquisa, percebia-se que para os salvadorenhos cabia à própria sociedade discutir e superar seus conflitos, pelo diálogo e negociação.

O debate nacional, ou "Assembleia Pública do Debate Nacional”, ocorreu em 3 e 4 de setembro de 1988; foi convocada pelo monsenhor Arturo Rivera Damas, arcebispo de San Salvador. Participaram do encontro representantes de sessenta forças sociais; os delegados votaram cento e sessenta e quatro teses; decidiu-se, por unanimidade, que os partidos incorporassem os pontos de consenso do Debate Nacional em suas plataformas; que as instituições ausentes e as forças sociais não convocadas favorecessem os acordos e se incorporassem ao debate nacional pela paz; que o órgão permanente do Debate Nacional realizasse as ações necessárias para cumprir os acordos e que prosseguisse o debate pela paz; que o governo e a FMLN respeitassem as deliberações do Debate Nacional, e de imediato acordassem o cessar-fogo e reativassem a negociação de paz (Debate Nacional de 1988). Isto é, havia um consenso nacional que apenas o amplo diálogo permitiria a retomada das negociações para a paz.

Mudanças decisivas ocorreram no mundo e em El Salvador no período 1986-1989: em 1986, um encontro entre Reagan e Gorbatchov enfraqueceu a ameaça comunista; em 1988, o presidente eleito, George Bush, analisou as insurreições mais como problema interno do que ameaça comunista (Sue-Montgomery \& Wade, 2006); o Debate Nacional de 1988 reafirmou a preferência pela paz, dado que a FMLN e o governo não puderam mais ignorar; em 1989, um relatório sobre o assassinato dos jesuítas (Envio, 1990a) afirmou que a relação EUA-El Salvador tinha se alterado porque "o bloco socialista desapareceu e a União Soviética está em graves dificuldades internas” (p. 20) e a guerrilha não era mais um instrumento da expansão soviética; nesse mesmo ano de 1989 um comandante da FMLN escreveu sobre sua preferência pela paz (Sue-Montgomery \& Wade, 2006). 
Apesar do abrandamento das condições, o período 1986-1989 foi incerto e ineficaz para as negociações de paz; motivo pelo qual a FMLN, simultaneamente, preparou sua ofensiva final e negociou o cessar-fogo. A ofensiva foi preparada desde fins de 1988, quando muitas armas e munição entraram em El Salvador; uma negociação, em setembro de 1989, propunha o cessar-fogo para 15 de novembro e o fim da guerra para 31 de janeiro de 1990 (Sue-Montgomery \& Wade, 2006). Mas a falta de seriedade nas negociações, a ausência de garantias e a continuidade nos ataques precipitou a ofensiva da FMLN em novembro de 1989. Se este foi um dos motivos para o batalhão Atacatl invadir a UCA, vitimando jesuítas e funcionários, por outro lado expôs a ineficiência das Forças Armadas e dos serviços de inteligência dos EUA para prevenir e/ou deter a ofensiva final da FMLN, demonstrando que a guerrilha e a FMLN estavam longe de serem vencidas.

Observa-se que, em paralelo à percepção da população sobre a necessidade do diálogo e do esgotamento do conflito armado em El Salvador, há indícios do fim da Guerra Fria e da diminuição da intervenção dos EUA na região; por outro lado, apesar da vontade popular que pedia o diálogo e do resfriamento dos ânimos entre EUA e URSS, ocorreu o recrudescimento do conflito em El Salvador, cessaram as condições para o diálogo, a FMLN concretizou sua ofensiva e o exército respondeu invadindo a UCA, vitimando professores e funcionários.

\section{Considerações finais}

O fim do comunismo, a queda do muro de Berlim, a internacionalização do capital, a globalização e mudanças na geopolítica mundial são alguns dos determinantes da nova ordem mundial, a partir dos anos 1990. No panorama salvadorenho, além das mudanças mundiais, a insurgência e a resistência da guerrilha e do povo, uma década de guerra civil e o próprio esgotamento do conflito, a repercussão internacional do assassinato dos jesuítas, as denúncias de violação dos direitos humanos e a Assembleia Nacional em diferentes níveis impulsionaram a retomada dos acordos de paz e fim do conflito.

Percebe-se uma polaridade extrema em El Salvador: de um lado, instabilidade política-econômica e a força histórica das oligarquias, ações de combate ao comunismo como inimigo ideológico, planos econômicos para manter a hegemonia sobre a região; de outro lado, clérigos lutando pela autonomia de um povo historicamente oprimido, dificuldades para subjugar a guerrilha e vencer o conflito, pesquisas do IUDOP perguntando ao povo o que de fato ocorria e o claro entendimento que a saída para a crise era o diálogo, apesar de toda a deterioração social do período. Esta complexidade dos eventos em El Salvador contribui para que se compreenda a importância do contexto para a análise e compreensão da obra e produção intelectual de Martín-Baró.

Martín-Baró atribuiu extremo valor à consulta popular e à circulação da informação como instrumento de conscientização (Martín-Baró, 1989b, 1990); desde 1986, o IUDOP já informava que a população reconhecia que o aniquilamento do inimigo não resolveria a situação, e esta posição foi reiterada por ocasião da Assembleia de 1988. Mas Martín-Baró reunia muitas das características indesejáveis na perspectiva do comando militar: jesuíta comprometido com a luta contra a opressão histórica dos povos latino-americanos; professor da UCA, com histórico de experiências comunitárias com os camponeses 
(Martín-Baró, 1973b); ele anunciava os resultados de suas pesquisas como meio de contrainformação; denunciava o terrorismo de estado e as políticas de intervenção, sempre em defesa da autonomia do povo salvadorenho.

A ênfase deste texto recai sobre os acontecimentos que determinaram a ordem dos eventos em El Salvador e marcaram a produção de Martín-Baró. Sua atuação como psicólogo buscou articular a teoria a partir da realidade social e foi pautada pelo estreito contato com as condições concretas de sua sociedade; suas pesquisas buscavam conhecer o que de fato pensavam os salvadorenhos e quais as necessidades da população; seu compromisso com a mudança social o conduziram a encontrar soluções para a identidade alienada de um povo marcado por diversos níveis de injustiça e desigualdade social. Seu legado nos é apresentado pelas mãos do próprio povo salvadorenho: após o fim da guerra civil, cidades foram reerguidas e outras mais foram criadas; algumas foram nomeadas por Segundo Montes, Ignácio Ellacuria e muitas delas receberam o nome de Ignácio Martín-Baró (Pico, 1993).

Martín-Baró foi um psicólogo inserido em um contexto específico, e sua obra representa esse momento. Espera-se que a partir desta perspectiva se amplie a compreensão de alguns dos seus temas prioritários e que a relevância social de sua atuação possa ser vista como parte integrante de sua teoria.

\section{Referências}

Gómez, J. A. (1971). Farabundo Martí: herói do povo de El Salvador. São Paulo: Anita Garibaldi.

Bologna, M. G. (2013). Banana [mis]representations: a gendered history of the United Fruit Company and las mujeres bananeras. Dissertação de Mestrado, Programa de Pós-gradução em Artes. Bowling Green State University, Ohio.

Bruit, H. H. (1985). Crônica de um massacre - uma greve operário-camponesa contra a United Fruit Co. Revista Brasileira de História, 5(10), 82-53.

Bucheli, M. (2005). Bananas and Business: The United Fruit Company in Colombia, 18992000. New York: New York University Press.

Bullmer-Thomas, V. (1996). The economic history of Latin America since independence. Cambridge: Cambridge Press University.

Comblim, J. (1980). A Ideologia da segurança nacional: o poder militar na América Latina. Rio de Janeiro: Civilização Brasileira.

Equipo Envio (1990a). El caso de los jesuítas ¿Quién los mandó matar? Envio Digital, 109, 10-33. Recuperado de http://www.envio.org.ni/articulo/645

Equipo Envio (1990b). El informe Moakley. Jesuitas mártires impulsan la paz. Envio Digital, 104, 10-33. Recuperado de http://www.envio.org.ni/articulo/633

Hardy, F. (1984). O pavio curto da América Central. Rio de Janeiro: Codecri.

Koeppel, D. (2007). Banana: the fate of the fruit that changed the world. S. L.: Penguin/Hudson Street Press.

Kolvenbach, P. H. (1989). Jesuitas mártires. Seis vidas por el pueblo. Envio Digital, 100, 1-14. Recuperado de http://www.envio.org.ni/articulo/614

López Cervantes, G. (2012). Mediterráneo Económico, 22,249-260. Recuperado de http://www. publicacionescajamar.es/pdf/publicaciones-periodicas/mediterraneo-economico/22/22-385.pdf 
Maira, L. (Org.). (1982). La politica Reagan y la crisis en Centroamerica. Centroamerica: EDUCA.

Marques, G. G. (2014). Cem anos de solidão. Rio de Janeiro: Record. (Original publicado em 1967)

Martín-Baró, I. (1968). El complejo de Macho, o el Machismo. ECA, 23(235), 38-42.

Martín-Baró, I. (1973a). Algunas repercusiones psico-sociales de la densidad demográfica em El Salvador. ECA, 28(293-294), 123-132.

Martín-Baró, I. (1973b). Psicología del campesino salvadoreño. ECA, 28(297-298), 476-495. Recuperado de http://www.uca.edu.sv/coleccion-digital-IMB/wp-content/uploads/2015/10/197 3Psicolog\%C3\%ADadelcampesinosalvadore\%C3\%B1oECA1973-28-297_298-476_495.pdf. Martín-Baró, I. (1981). La guerra civil em El Salvador. ECA, 36(387-388), 17-32. Recuperado de http://www.uca.edu.sv/coleccion-digital-IMB/articulo/la-guerra-civil-en-el-salvador/

Martín-Baró, I. (1983a). Los sectores médios ante el plan Reagan. Uma pesperctiva sombría. $E C A, 38(415-416), 517-522$. Recuperado de http://www.uca.edu.sv/coleccion-digital-IMB/articulo/los-sectores-medios-ante-el-plan-reagan-una-perspectiva-sombria/

Martín-Baró, I. (1983b). Polarización social en El Salvador. ECA, 38(412), 129-142.

Martín-Baró, I. (1984a). El terrorismo de estado norte americano. ECA, 39(433), 813-816.

Recuperado de http://www.uca.edu.sv/coleccion-digital-IMB/articulo/el-terrorismo-del-estado-norteamericano/

Martín-Baró, I. (1984b). Guerra y salud mental. ECA, 39(429-430), 503-514.

Martín-Baró, I. (1987). El latino indolente: carácter ideológico del fatalismo latinoamericano. In A. Aron \& S. Corne (Eds.), Writings for a liberation psychology (pp. 198-220). Cambridge: Harvard University Press.

Martín-Baró, I. (1988). La violencia política y la guerra como causas del trauma psicossocial en El Salvador. Revista de Psicología de El Salvador, 7(28), 123-141.

Martín-Baró, I. (1989a). La institucionalización de la guerra. Revista de Psicologia de El Salvador, 8(33), 223-245.

Martín-Baró, I. (1989b). La opinión pública salvadoreña. San Salvador: UCA. Recuperado de http://www.uca.edu.sv/coleccion-digital-IMB/wp-content/uploads/2015/11/1989-@-La-opinion-publica-salvadore\%C3\%B1a-1987-1988.pdf

Martín-Baró, I. (1990). La Encuesta de opinión pública como instrumento desideologizador. Revista de Psicologia de El Salvador, 9(35), 9-22. Recuperado de http://www.uca.edu.sv/coleccion-digital-IMB/articulo/la-encuesta-de-opinion-publica-como-instrumento-desideologizador/

Martín-Baró, I. (1996). O papel do psicólogo. Estudos de Psicologia, 2(1), 7-27.

May, S. \& Plaza, G. (1958). The case study of the United Fruit in Latin America. New York: National Planning Association. Recuperado de https://archive.org/details/unitedfruitcompa00maysrich

Miles, S. \& Ostertag, B. (1991). The FMNL: new thinking. In A. Sundaram \& G. Gelber (Eds.), A decade of war. El Salvador confronts de future (pp. 216-246). London: Catholic Institute for International Relations.

Montagna, W. (1986). A doutrina da segurança nacional. Projeto História. Revista do Programa de Estudos Pós-Graduados de História, 6, 29-40.

Neruda, P. (2010). Canto geral. São Paulo: Círculo do livro. (Original publicado em 1950). Recuperado de https://dialogosliterarios.files.wordpress.com/2014/11/canto-geral.pdf Padrós, E. S. (2007). As escolas militares dos Estados Unidos e a pentagonização das Forças Armadas da América Latina. Outros Tempos, 1, 13-31. Recuperado de http://www.outrostempos.uema.br/vol_especial/dossieespecialart02.pdf 
Pico, J. H. (1993). La cosecha de los 80 en Centroamérica. In M. E. C. Arzú \& R. C. Quintana (Coords.), Centroamérica. Balance de la decada de los 80. Una perspectiva regional (pp. $417-$ 440). Madrid: Fundacion CEDEAL.

Rosa, H. \& Suay, R. (1986). El nuevo modelo norteamericano para Centro América: el caso de El Salvador. Boletim de Ciencias Económicas y Sociales, 74(1), 7-43. Recuperado de http:// www.uca.edu.sv/boletines/upload_w/file/boletines/4fd269be2811 carticulos.pdf

Siegfried, A. (1945). Suez, Panama et les routes maritimes mondiales. Paris: Armand Colin. Recuperado de http://classiques.uqac.ca/classiques/siegfried_andre/suez_panama/suez_panama.pdf

Sillva, B. F. A. (2016). A identidade latino-americana em Cem Anos de Solidão (1967), de Gabriel García Márquez. Epígrafe, 3(3), 157-170. Recuperado de https:/www.revistas.usp.br/ epigrafe/article/view/111490/118460

Sobrino, J. (1991). The role of the Church. In A. Sundaram \& G. Gelber (Eds.), A decade of war. El Salvador confronts de future (pp. 167-181). London: Catholic Institute for International Relations.

Sue-Montgomery, T. \& Wade, C. (2006). A revolução salvadorenha: da revolução à reforma. São Paulo: Editora UNESP.

Vergara, A. M. F. (2010). A United Fruit Company e a Guatemala de Miguel Angel Asturias Dissertação de Mestrado, Programa de Pós-graduação em História Social, Universidade de São Paulo, São Paulo.

\author{
MARIA FERNANDA COSTA WAENY \\ http://orcid.org/OOOO-0002-7220-6281 \\ Psicóloga. Doutora em Psicologia Social pela PUCSP. Docente do Mestrado em \\ Psicologia-Psicossomática da Universidade Ibirapuera-SP. Tem experiência na área de \\ Psicologia, com ênfase em Psicologia Social, História da Psicologia, Psicologia Histórica \\ e Ignace Meyerson, estresse ocupacional e Riscos Psicossociais. \\ Endereço institucional: Av. Interlagos, 1329 - $4^{\circ}$ andar - Chácara Flora, São \\ Paulo - SP, 04661-100. \\ E-mail: fernandawaeny@gmail.com
}

\footnotetext{
CIBELE MARIANO VAZ DE MACÊDO

http://orcid.org/OOOO-0002-4130-2115

Psicóloga. Doutora em Psicologia Social pela Universidade do Estado do Rio de Janeiro. Pesquisadora Associada ao Núcleo de Estudos Relações Raciais: memória, identidade e imaginário, na PUC/SP. Docente do Curso de Mestrado em PsicologiaPsicossomática na Universidade Ibirapuera-SP. Experiência na área de Psicologia, com ênfase em Psicologia Social, atuando principalmente nos seguintes temas: processos de subjetivação, território, mobilidade, narrativa, estresse ocupacional e riscos psicossociais.

E-mail: cibelevaz@gmail.com
} 
Submissão em: 06/11/2017

Histórico

Revisão em: 08/03/2019

Aceite em: 14/03/2019

Concepção: MFCW; CMVM

Coleta de dados: MFCW; CMVM

Análise de dados: MFCW; CMVM

Contribuição dos autores

Elaboração do manuscrito: MFCW; CMVM

Crítico revisões de conteúdo intelectual importante:

MFCW; CMVM

Final aprovação do manuscrito: MFCW; CMVM

Financiamento Não houve

Consentimento de uso de imagem

Não se aplica

Aprovação, ética e consentimento

Não se aplica 